\title{
Tuning nitrogen functionalities in catalytically grown nitrogen-containing carbon nanotubes
}

\author{
S. van Dommele ${ }^{a}$, A. Romero-Izquirdo ${ }^{a}$, R. Brydson ${ }^{b}$, K.P. de Jong ${ }^{a}$, J.H. Bitter ${ }^{a, *}$ \\ ${ }^{a}$ Inorganic Chemistry and Catalysis, Department of Chemistry, Faculty of Sciences, Utrecht University, The Netherlands \\ ${ }^{b}$ Institute for Materials Research, Faculty of Engineering, University of Leeds, Leeds LS2 9JT, United Kingdom
}

\section{A R T I C L E I N F O}

Article history:

Received 15 July 2007

Accepted 30 October 2007

Available online 7 November 2007

\begin{abstract}
A B S T R A C T
Nitrogen-containing carbon nanotubes (NCNT) were grown from acetonitrile, pyridine or $\mathrm{N}, \mathrm{N}$-dimethylformamide over a supported $\mathrm{Fe}-$, Co- or $\mathrm{Ni}$ catalyst in the temperature range 823-1123 K. The physico-chemical properties of the obtained NCNT, such as the C/N ratio or the nitrogen type, were related to the synthesis parameters. It was found that the $\mathrm{C} / \mathrm{N}$ ratio increased with increasing temperature which could be related to the thermodynamic stabilities of the metal-carbides and metal nitrides. Also the type of nitrogen present in the graphene layer changed with increasing temperature from predominantly pyridinic- to quaternary nitrogen. NCNT obtained with the Fe catalyst showed bamboo morphology regardless of the $\mathrm{C} / \mathrm{N}$ source or growth temperature while straight tubes were obtained with the Co- or Ni catalyst. We propose that this difference in morphology can be explained by the thermodynamic stabilities of the different metal-carbides, leading to a 'pulsating' growth in the case of Fe as opposed to a more continuous growth in the case of Co or Ni.

(c) 2007 Elsevier Ltd. All rights reserved.
\end{abstract}

\section{Introduction}

Altering the physico-chemical properties of Carbon Nanotubes (CNT) has become an important topic in nanotechnology as their possibilities for application expand, for example as electronic devices [1-3], catalyst support material [4-7] or solid base catalyst [8]. This can be achieved by changing the local electron density in these materials by introducing hetero atoms such as nitrogen substituting carbon in the graphene sheets that form CNT. Various methods have been applied to incorporate nitrogen into CNT [8-25]. Among these are magnetron sputtering [11,13], laser ablation [14,15], pyrolysis of mixtures of organometallic- and nitrogen containing organic compounds [16-20] and chemical vapor deposition (CVD) of nitrogen-containing hydrocarbons over a heterogeneous iron, cobalt or nickel catalysts [8,21-25]. Depending on the technique used, various amounts and types of nitrogen in the resulting nitrogen-containing CNT (NCNT) have been found and different yields and morphologies of the NCNT occur. For example $\mathrm{CN}_{x}$ films and/or tubes with nitrogen concentrations up to 26 at $\%$ have been synthesized using magnetron sputtering [13]. However, various morphologies were found such as amorphous nitrogen doped carbon or NCNT on $\mathrm{CN}_{x}$ films. Pyrolysis of iron-, cobalt- or nickel phthalocyanines between 1023 and $1273 \mathrm{~K}$ produced NCNT with a rather narrow diameter distribution and nitrogen concentrations up to 8 at\%. It was observed that an increase in temperature caused a decrease in nitrogen concentration [17]. Kudashov et al. [16] and Choi et al. [17] reported that the wall thickness of the tubes varied with the catalyst composition suggesting tunability of NCNT morphology. Kim et al. [21] reported the synthesis of double-walled NCNT and a nitrogen concentration up to 5 at\% using CVD of ammonia and methane mixtures over a magnesium oxide supported iron/molybdenum catalyst. Other CVD experiments where the type of precursor, catalyst or support was varied produced NCNTwith

\footnotetext{
* Corresponding author: Fax: +31 302511027

E-mail address: j.h.bitter@uu.nl (J.H. Bitter).
}

0008-6223/\$ - see front matter @ 2007 Elsevier Ltd. All rights reserved. doi:10.1016/j.carbon.2007.10.034 
diameters ranging from 10 to $80 \mathrm{~nm}$ and nitrogen concentrations up to 10 at\%. Increasing the amount of nitrogen above 10 at\% seems to be possible but it is challenging. Several authors report the synthesis of NCNT with a high nitrogen concentration between 10 and 20 at\% [20,25]. According to these authors the key to achieving a high nitrogen content in NCNT is using $\mathrm{C} / \mathrm{N}$ precursors with non-saturated $\mathrm{C}-\mathrm{N}$ bonds like acetonitrile or $\mathrm{N}, \mathrm{N}$-dimethylformamide. It must be noted, however, that in some cases NCNT were obtained where only a fraction of the sample consisted of NCNT with high nitrogen concentration [20] or that the material was unstable and a loss of nitrogen occurred over time [25]. In other cases $\mathrm{CN}_{x}$ thin films or diamond like structures, i.e., mainly $\mathrm{sp}^{3}$ hybridisation, have been synthesized with values of $x$ between 0.1 and $1.3[11,13,15,26,27]$. However, the graphitic nature of the material decreased with increasing nitrogen content resulting in some cases in small $\mathrm{CN}_{x}$ arrays embedded in an amorphous carbon matrix [27]. Calculations suggested that above a nitrogen incorporation of 20 at $\%$ into the graphitic matrix the structure distorts and loses its stability $[28,29]$. It seems that an energy barrier exists against $\mathrm{N}$ incorporation which is decreased by relaxation of the system to a non-planar structure. On the other hand, according to calculations of Snis et al. [30] a graphitic form of $\mathrm{C}_{3} \mathrm{~N}_{4}$ is possible.

From all studies it becomes clear that it is rather difficult to obtain uniform NCNT with a high nitrogen concentration, i.e., above 20 at\%, with conventional techniques like chemical vapor deposition. However, to our opinion CVD is an attractive route for the synthesis of carbon nanomaterials since it is relatively easy to execute and allows large scale production of the materials $[31,32,18]$.

At least three types of nitrogen are found in NCNT. These are pyridinic nitrogen, pyrrolic nitrogen and quaternary nitrogen $[9,33,34]$. The pyridinic $\mathrm{N}$ type is an $\mathrm{sp}^{2}$ hybridized nitrogen atom located at the edges or at defects of the graphene sheets (Fig. 1A) [35]. These pyridinic nitrogen atoms have a localized electron lone pair which and are active in base catalyzed reactions [8]. Therefore the optimization of the amount of pyridinic nitrogen is important for catalysis. The pyrrolic $\mathrm{N}$ type is $\mathrm{sp}^{3}$ hybridized and part of a five membered ring structure (Fig. 1B). The quaternary $\mathrm{N}$ is a carbon substituted nitrogen atom located in the graphene sheet (Fig. 1C). A fourth type has been reported and labeled as $\mathrm{N}-\mathrm{X}$ species (Fig. 1D), believed to be an oxidized type of pyridinic $N[33,34]$. Although the different types of nitrogen present in the NCNT have been described, mainly the increase of the amount of nitrogen incorporated has been the focus in many studies.

The introduction of nitrogen in the graphene layers of the carbon nanotube takes place during synthesis and therefore
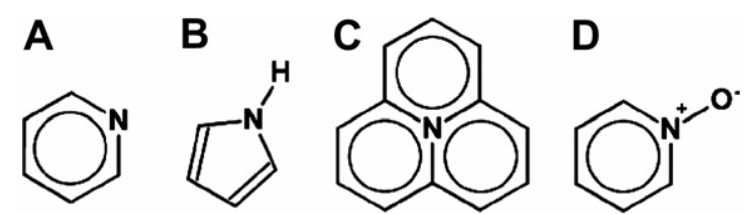

Fig. 1 - Types of nitrogen species found in NCNT: (A) pyridinic, (B) pyrrolic, (C) quaternary and (D) oxidized pyridinic. the conditions in the catalytic growth process are important. In the process of NCNT synthesis three stages can be envisaged during growth, i.e., (1) decomposition of the precursor to surface carbon and nitrogen atoms, (2) diffusion/migration of these atoms through/over the metal and (3) formation of the NCNT. In order to be able to tune the physical-chemical properties of the NCNT one needs to influence one or more of the above mentioned steps. It is likely that changes in synthesis parameters, specifically temperature, growth catalyst and N/C-source, will affect the physical-chemical properties of the resulting NCNT, e.g., the graphitic character or amount and type of nitrogen incorporated. For example, the decomposition rate of the $\mathrm{C} / \mathrm{N}$ source will affect the rate of supply of carbon- and nitrogen atoms and thus be of influence in the NCNT growth. Diffusion/migration of carbon over/ through the catalyst is determined by the metal and probably the temperature. In literature many reports can be found dealing with the solubility of carbon in transition metals connected to phase diagrams of $\mathrm{Fe}_{3} \mathrm{C}, \mathrm{Co}_{2} \mathrm{C}$ and $\mathrm{Ni}_{3} \mathrm{C}$ [36-39]. A thorough examination of the effect of $\mathrm{C} / \mathrm{N}$ precursor, catalyst and growth temperature on the physical-chemical properties of the NCNT, in particular amount and type of nitrogen incorporated, is required to be able to tune the NCNT's features. Reports in literature have often focused on the effect of just one synthesis parameter. In this contribution several aspects of NCNT growth, i.e., the influence of the $\mathrm{C} / \mathrm{N}$ source, catalyst and synthesis temperature, and the effect thereof on the NCNT morphology, amount of nitrogen incorporated and the type of nitrogen functions present will be related. We used three main variables in the synthesis of NCNT, i.e., C/N source, catalyst and temperature. As $\mathrm{C} / \mathrm{N}$ source we applied acetonitrile (ACN, sp-hybridized $\mathrm{N}$ ), pyridine (PYR, $\mathrm{sp}^{2}$-hybridized $\mathrm{N}$ ) and $\mathrm{N}, \mathrm{N}$-dimethylformamide (DMF, $\mathrm{sp}^{3}$-hybridized $\mathrm{N}$ ). As growth catalyst iron, cobalt and nickel were used and the growth temperature was varied between 823 and $1123 \mathrm{~K}$. The physical and chemical properties of the resulting material are examined with appropriate characterization techniques.

\section{Experimental}

\subsection{Catalyst preparation}

Silica or alumina supported iron-, cobalt- and nickel catalysts were synthesized using homogeneous deposition precipitation (HDP) $[40,41]$. In a double-walled precipitation vessel $10 \mathrm{~g}$ of the support, i.e., silica Aerosil 200 or alumina, was suspended in a mixture of $1 \mathrm{~L}$ demi-water, a predetermined amount of iron-, cobalt- or nickel nitrate (which would result in a metal loading of 20 at\%) and urea (threefold the molar amount of the metal nitrate). The mixture was then heated to $363 \mathrm{~K}$ under continuous stirring and maintained at that temperature for $16-20 \mathrm{~h}$. The suspension was filtered and the precipitate was re-suspended in demi-water to remove excess urea. The precipitate was then dried at $393 \mathrm{~K}$ and a sieve fraction of the pre-catalyst $(150 \mu \mathrm{m} \leqslant x \leqslant 425 \mu \mathrm{m})$ was calcined afterwards at $873 \mathrm{~K}$ in static air for $3 \mathrm{~h}$.

In addition silica supported nickel- and cobalt catalysts were prepared using the wet impregnation technique. Silica Aerosil 200 was heated under vacuum to $423 \mathrm{~K}$, maintained 
at that temperature for $2 \mathrm{~h}$ and cooled to room temperature in nitrogen afterwards. Next, a solution $\left(7 \mathrm{~mL} \mathrm{~g}^{-1}\right.$ silica) of nickel nitrate hexahydrate or cobalt nitrate hexahydrate (to obtain a $20 \mathrm{wt} \%$ metal loading), dissolved in a mixture of water and ethanol $(15 / 85 \mathrm{v} / \mathrm{v})$, was added to the silica under continuous stirring. The solution was evaporated at room temperature for $20 \mathrm{~h}$ and then further dried at $333 \mathrm{~K}$ for $24 \mathrm{~h}$. A sieve fraction of the pre-catalyst $(150 \mu \mathrm{m} \leqslant x \leqslant 425 \mu \mathrm{m})$ was calcined at $873 \mathrm{~K}$ in static air for $3 \mathrm{~h}$.

\subsection{NCNT synthesis}

About $0.5 \mathrm{~g}$ of catalyst was loaded in a vertical quartz reactor and reduced between 873 and $973 \mathrm{~K}$ for $2 \mathrm{~h}$ in a $20 \% \mathrm{H}_{2} / \mathrm{He}$ flow (total $100 \mathrm{~mL} \mathrm{~min}^{-1}$ ). Next, the reduced catalyst was kept at its Tamman temperature, i.e., $905 \mathrm{~K}(\mathrm{Fe}), 885 \mathrm{~K}(\mathrm{Co}), 865 \mathrm{~K}$ (Ni), in a helium flow for one hour. NCNT were grown from acetonitrile (ACN), pyridine (PYR) or $\mathrm{N}, \mathrm{N}$-dimethylformamide (DMF) between 823 and $1123 \mathrm{~K}$ using a helium flow ( $50 \mathrm{~mL} \mathrm{~min}^{-1}$ ) saturated by bubbling through the liquid precursor at $303 \mathrm{~K}$. After $16-20 \mathrm{~h}$ the growth reaction was stopped by flushing the reactor with a helium flow $\left(50 \mathrm{~mL} \mathrm{~min}^{-1}\right)$ and cooling to room temperature after which the amount of NCNT was determined. The yield of material was expessed as gram NCNT per gram of metal in the growth catalyst $\left(\mathrm{g}_{\mathrm{NCNTt}} / \mathrm{g}_{\mathrm{M}}\right)$.

The growth catalyst was removed by subsequent refluxing the raw product in $1 \mathrm{M} \mathrm{KOH}$ and $25 \% \mathrm{HCl}$ solution. The NCNT were thoroughly washed with demi-water after each step. The purified product was dried at $333 \mathrm{~K}$ in air. Samples were labeled according to metal, temperature and precursor; Co823ACN for example refers to NCNT grown from acetonitrile at $823 \mathrm{~K}$ using a cobalt catalyst. NCNT grown from a catalyst prepared by wet impregnation are denoted with the extension -WI.

\subsection{Characterization}

Prior to their characterization the growth catalysts were reduced in a $20 \% \mathrm{H}_{2} / \mathrm{He}$ flow at 873 (Fe and Co) and $973 \mathrm{~K}(\mathrm{Ni})$. After $2 \mathrm{~h}$ the temperature was decreased to room temperature and the reducing atmosphere was first changed to $\mathrm{He}$ and subsequently $\mathrm{O}_{2} / \mathrm{He}(100 \mathrm{~mL} / \mathrm{min})$ with the oxygen concentration increasing from $0.1 \%$ to $20 \%$ for the $\mathrm{Ni} / \mathrm{SiO}_{2}$ catalyst. The $\mathrm{Co}$ and $\mathrm{Fe}$ catalysts were passivated in $\mathrm{CO}_{2} / \mathrm{He}(5 \%$, total flow $100 \mathrm{~mL} / \mathrm{min}$ ) for $20 \mathrm{~h}$. The catalyst characteristics were analyzed with $\mathrm{X}$-ray diffraction (XRD) and $\mathrm{H}_{2}$-chemisorption.
X-ray diffractograms of powdered samples were taken using an Enraf-Nonius CPS 120 powder diffraction apparatus with $\mathrm{Co}(\mathrm{K} \alpha)$ radiation of $1.79 \AA$. Hydrogen chemisorption analysis was performed with a micromeretics ASAP 2010C apparatus. The growth catalysts were dried for $2 \mathrm{~h}$ at $393 \mathrm{~K}$ and then re-reduced at $973 \mathrm{~K}$ in hydrogen for $2 \mathrm{~h}$ with a heating rate of $5 \mathrm{~K} \mathrm{~min}^{-1} . \mathrm{H}_{2}$ adsorption isotherms were measured at $593 \mathrm{~K}, 423 \mathrm{~K}$ and $423 \mathrm{~K}$ for, respectively, Fe, Co and Ni. To determine the metal loading of the growth catalysts $\mathrm{X}$-Ray Fluorescence analysis was performed using a Goffin Meyvis Spectro X-lab 2000.

The N/C atomic ratio in the NCNTwas determined by X-ray photoelectron spectroscopy (XPS) using a Vacuum Generators XPS system operating with $\mathrm{Al}\left(\mathrm{K}_{\alpha}\right)$ radiation. The raw data were corrected for charging using the binding energy of graphite at $284.4 \mathrm{eV}$. Peak areas were determined after background substraction using Shirley's method and fitting the spectra with Gaussian curves. The amount of nitrogen incorporated was calculated from the peak areas of the C1s- and N1s peaks after correcting for differences in sensitivity using sensitivity factors of 0.540 and 0.972 for $C$ and $N$, respectively. The N1s peak was deconvoluted into contributions of pyridinic N (398.4-399.0 eV), pyrrolic N (400.0-400.6 eV), quaternary $\mathrm{N}(401.1-401.7 \mathrm{eV})$ and N-O species (402.0-405.0 eV).

The morphology of the NCNT was examined by transmission electron microscopy (TEM) using a Tecnai20FEG electron microscope. Crushed NCNT were suspended in ethanol and a drop of the suspension was deposited on a copper grid and the solvent was evaporated. Micrographs were taken at $200 \mathrm{kV}$. Additional TEM studies including energy filtered TEM (EFTEM) elemental mapping of the carbon and nitrogen distributions in NCNT was undertaken on an FEI CM200 field emission transmission electron microscope operated at $200 \mathrm{kV}$ and fitted with a GIF200 Gatan imaging filter.

\section{Results}

For the synthesis of the NCNT growth catalyst were prepared using either homogeneous deposition precipitation (HDP) or wet impregnation (WI). Some of the characteristics of the catalysts after reduction and passivation have been compiled in Table 1.

Table 1 shows the metal particle size of the prepared catalysts. The average particle size observed with TEM varies between 5 and $10 \mathrm{~nm}$. XRD showed that in most cases, except for $\mathrm{Ni} / \mathrm{SiO}_{2}$, that the particle size distribution was bimodal. This was inferred from the shape of the XRD reflection, i.e.,

Table 1 - Catalyst Characteristics after reduction at $973 \mathrm{~K}$

Catalyst Metal loading (wt\%)

Metal particle size

TEM average size $(\mathrm{nm})$ TEM size range $(\mathrm{nm}) \quad \mathrm{XRD}^{\mathrm{a}}(\mathrm{nm})$

\begin{tabular}{llcccc}
\hline $\mathrm{Fe} / \mathrm{Al}_{2} \mathrm{O}_{3}$ & 28 & 10 & $4-20$ & $10 ; 23$ & bcc \\
$\mathrm{Co} / \mathrm{SiO}_{2}$ & 21 & 5 & $3-10$ & $3 ; 9$ & $\mathrm{fcc} / \mathrm{hcp}$ \\
$\mathrm{Co} / \mathrm{SiO}_{2}-\mathrm{WI}$ & 20 & - & - & $11 ; 23$ & $\mathrm{fcc} / \mathrm{hcp}$ \\
$\mathrm{Ni} / \mathrm{SiO}_{2}$ & 24 & 7 & $3-20$ & 5 & $\mathrm{fcc}$ \\
$\mathrm{Ni} / \mathrm{SiO}_{2}-\mathrm{Wi}$ & 20 & 10 & $5-30$ & $12 ; 28$ & $\mathrm{fcc}$
\end{tabular}

a Bimodal distribution, left number size of small particles, right number size of large particles. 
superposition of a broad signal and a narrow signal. After deconvolution, the two average particle sizes were obtained. The Co and Ni catalyst prepared by HDP showed the smallest particles (5 $\mathrm{nm}$ for $\mathrm{Ni}$ and 3-9 $\mathrm{nm}$ for Co). Unfortunately the Fe particles were larger (10-23 nm) even though HDP was used as preparation technique. Both the impregnated catalysts show also large particles $(11-28 \mathrm{~nm})$ as intended. These observations were supported by the TEM results.

NCNT were grown using different growth catalysts, C/Nsources and temperatures. A comprehensive overview of the growth conditions and of the physico-chemical properties of the prepared NCNT is shown in Table 2. When discussing

\section{Table 2 - Growth conditions, yield and properties of NCNT}

Catalyst Precursor Temperature $(\mathrm{K})$ Yield $\left(\mathrm{g}_{\mathrm{NCNT}} / \mathrm{g}_{\mathrm{M}}\right)$ Purity Average tube diameter $(\mathrm{nm})$ Amount $\mathrm{N}^{\mathrm{b}}\left(\mathrm{mmol} \mathrm{g}^{-1}\right) \quad \mathrm{N}_{\mathrm{P}} / \mathrm{N}_{\mathrm{Q}}{ }^{\mathrm{b}}$

\begin{tabular}{|c|c|c|c|c|c|c|c|}
\hline \multirow[t]{9}{*}{$\mathrm{Fe} / \mathrm{Al}_{2} \mathrm{O}_{3}$} & ACN & 823 & 0 & & & & \\
\hline & & 923 & 23 & + & 12 & 5.6 & 0.9 \\
\hline & & 1023 & 25 & + & 17 & 5.2 & 1.0 \\
\hline & PYR & 923 & 42 & + & 12 & 2.8 & 2.8 \\
\hline & & 1023 & 42 & + & 19 & 5.0 & 1.0 \\
\hline & & 1123 & 48 & - & - & 3.2 & 1.0 \\
\hline & DMF & 823 & 0 & & & & \\
\hline & & 923 & 4 & + & 14 & - & - \\
\hline & & 1023 & 0 & & & & \\
\hline \multirow[t]{9}{*}{$\mathrm{Co} / \mathrm{SiO}_{2}$} & ACN & 823 & 10 & + & 16 & 7.4 & 2.2 \\
\hline & & 923 & 17 & + & 17 & 4.0 & 1.0 \\
\hline & & 1023 & 25 & + & 18 & 4.3 & 0.6 \\
\hline & PYR & 923 & 8 & \pm & 18 & 7.5 & 2.0 \\
\hline & & 1023 & 6 & \pm & 62 & 7.4 & 1.5 \\
\hline & & 1123 & 5 & - & - & 5.6 & 0.9 \\
\hline & DMF & 823 & 4 & + & 14 & 1.8 & 0.8 \\
\hline & & 923 & 3 & + & 14 & 1.6 & 0.7 \\
\hline & & 1023 & - & & & & \\
\hline \multirow[t]{9}{*}{$\mathrm{Ni} / \mathrm{SiO}_{2}$} & ACN & 823 & 10 & + & 12 & 5.0 & 1.7 \\
\hline & & 923 & 14 & + & 14 & 4.6 & 1.5 \\
\hline & & 1023 & 6 & \pm & - & 3.6 & 0.6 \\
\hline & PYR & 923 & 4 & \pm & 13 & 7.1 & 1.8 \\
\hline & & 1023 & 6 & \pm & - & 7.1 & 1.3 \\
\hline & & 1123 & 6 & - & - & 6.4 & 1.4 \\
\hline & DMF & 823 & 2 & + & 12 & 1.8 & - \\
\hline & & 923 & 0 & & & & \\
\hline & & 1023 & - & & & & \\
\hline
\end{tabular}

a (+) pure NCNT, ( \pm ) NCNT and amorphous C, (-) amorphous C.

$\mathrm{b}$ Determined from XPS data.
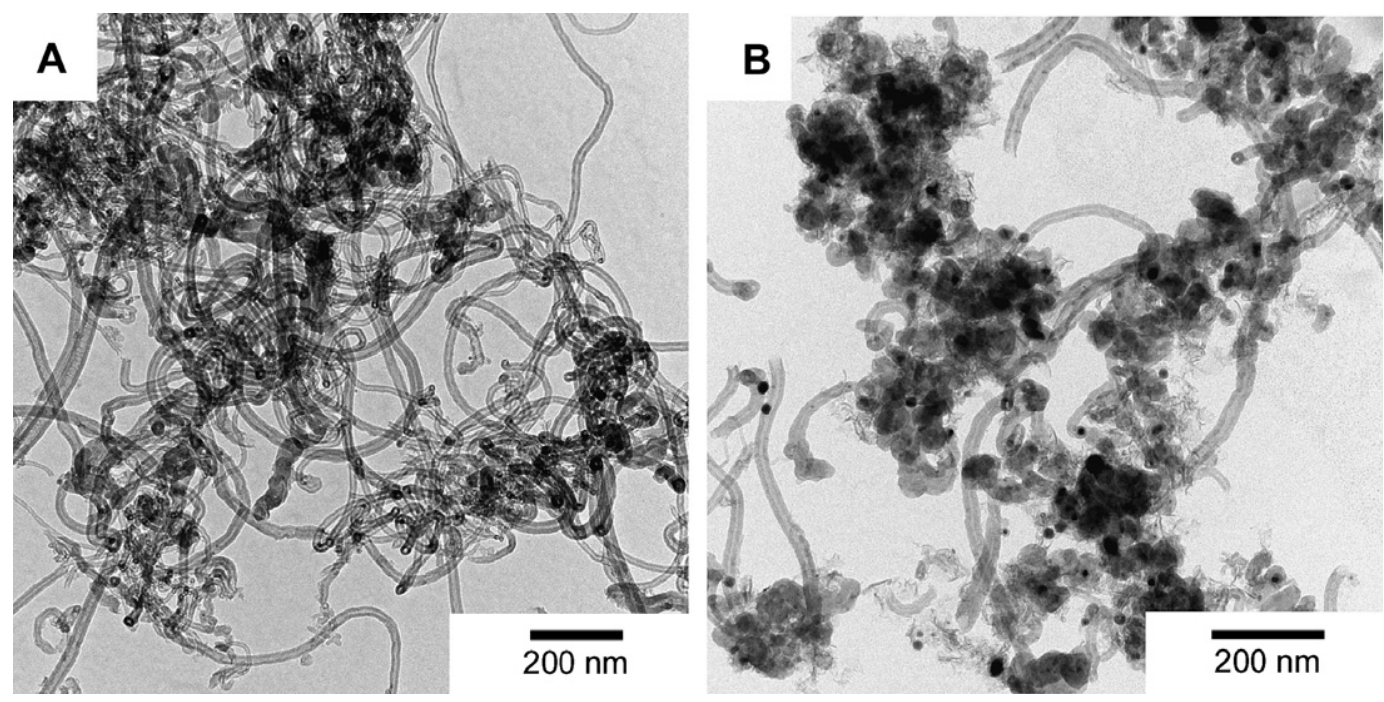

Fig. 2 - TEM micrograph of NCNT grown from ACN (A) and NCNT plus amorphous carbon depositions grown from PYR (B) over $\mathrm{Co} / \mathrm{SiO}_{2}$ at $923 \mathrm{~K}$. 
the synthesis parameters the quality i.e., purity of the samples is important (Table 2; purity). Fig. 2 shows TEM micrographs of NCNT grown at $923 \mathrm{~K}$ over $\mathrm{Co} / \mathrm{SiO}_{2}$ either from ACN or PYR. Clearly the ACN sample shows only tubular materials (purity labelled as + in Table 2) while in the NCNT prepared from PYR next to tubular material a significant amount of amorphous carbonaceous material is observed (purity labelled as \pm in Table 2). For all samples compiled in Table 2 the purity of the sample was qualitatively judged on the basis of a significant amount (10-20) of TEM images.

We will describe in detail now the influence of temperature, C/N source and metal separately with the focus on product yield, morphology and composition.

\subsection{Influence of temperature}

For NCNT prepared from ACN it was observed that the yield of NCNT increased with temperature, irrespective of the metal catalyst used. For the other growth gases (DMF, PYR) this trend is not clear possible due to the formation of amorphous materials as listed for a number of cases in Table 2 .

The average diameters of the formed NCNT varied between 12 and $18 \mathrm{~nm}$ irrespective of the growth temperature,

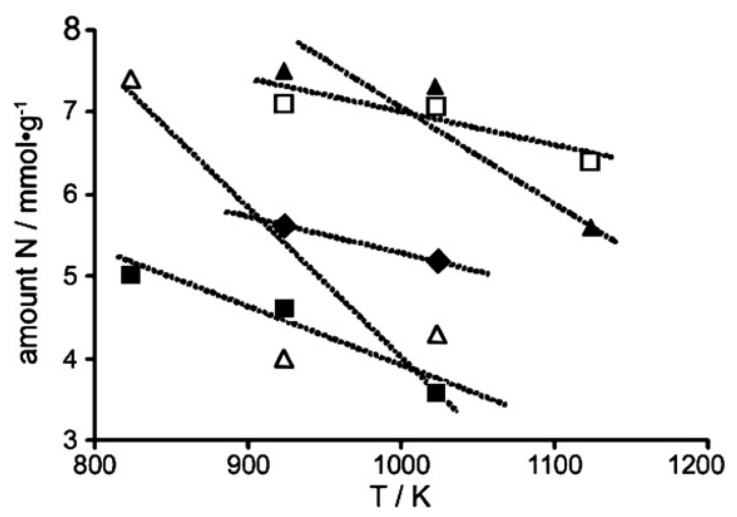

Fig. 3 - Temperature dependency of the amount of $\mathbf{N}$ in NCNT from catalyst-precursor series; Fe-ACN $(\diamond)$, Co-ACN $(\triangle)$, Ni-ACN ( $\square)$, Co-PYR (A) and Ni-PYR ( $\square)$. growth gas or carbon source. Only over $\mathrm{Co} / \mathrm{SiO}_{2}$ using PYR tubes of $60 \mathrm{~nm}$ were observed.

The amount of nitrogen incorporated in the NCNT varied between 1.6 and $7.4 \mathrm{mmol} \mathrm{g}^{-1}$ which corresponds to a N/C atomic ratio between 0.02 and 0.10 . In general, the N/C ratio decreased with increasing growth temperature as shown in Fig. 3 (please note that for DMF too few data points were obtained and were therefore omitted from the figure). This does not only hold for the pure NCNT materials but also for the less well defined (i.e., more amorphous) materials.

The distribution of nitrogen and carbon throughout an NCNT sample (Co823ACN) was determined by three window elemental mapping using EFTEM. Fig. 4A shows a zero loss filtered bright field image of the NCNT. In addition the elemental maps are displayed in Fig. 4B (carbon K-edge) and Fig. 4C (nitrogen $\mathrm{K}$-edge). As can be seen from Fig. $4 \mathrm{C}$ the nitrogen atoms seem to be located mainly on the outer parts of the NCNT. The N/C atomic ratio was found to be between 0.01 and 0.05 and was consistent with the XPS results shown in Table 2. The associated EELS nitrogen K-edge spectrum was found to be consistent with the presence of $\mathrm{sp}^{2}$-bonded pyridinic nitrogen.

Fig. 5 shows typical N1s XPS spectra between 395 and $405 \mathrm{eV}$ of Co823ACN and Co923ACN. Four different signals were fitted to these spectra representing pyridinc nitrogen $\left(\mathrm{N}_{\mathrm{P}} ; 398 \mathrm{eV}\right)$, quaternary nitrogen $\left(\mathrm{N}_{\mathrm{Q}} ; 400 \mathrm{eV}\right)$, pyrrolic nitrogen $\left(\mathrm{N}_{\mathrm{PYR}} ; 399 \mathrm{eV}\right)$ and nitrogen oxides $\left(\mathrm{N}_{\mathrm{Ox}} ; 401-405 \mathrm{eV}\right)$ $[34,42,43]$. As can be seen in this figure the N1s signal of the two NCNT samples is rather different showing the sensitivity of the technique for the type of nitrogen. The $\mathrm{N}_{\mathrm{P}} / \mathrm{N}_{\mathrm{Q}}$ ratio is large in Co823ACN and lower for Co923ACN i.e., for the sample prepared at higher temperature. Table 2 shows that this is a general trend, with increasing growth temperature the $\mathrm{N}_{\mathrm{P}} / \mathrm{N}_{\mathrm{Q}}$ ratio decreases.

Besides pyridinic $\mathrm{N}$ and quaternary $\mathrm{N}$ two more nitrogen functionalities were found in all NCNT with binding energies around 400 and $403 \mathrm{eV}$ which could be ascribed, respectively, to pyrrolic $\mathrm{N}$ and $\mathrm{N}$-oxides [34]. The relative amount of the latter type was rather low for the NCNT grown from Co or Ni, less than $10 \%$ of the total N1s peak area, and remained fairly constant in all NCNT grown between 823 and $1123 \mathrm{~K}$. For the Fe grown NCNT the amount varied between $8 \%$ and $38 \%$. The relative amount of pyrrolic $\mathrm{N}$ varied between $5 \%$ and $42 \%$.
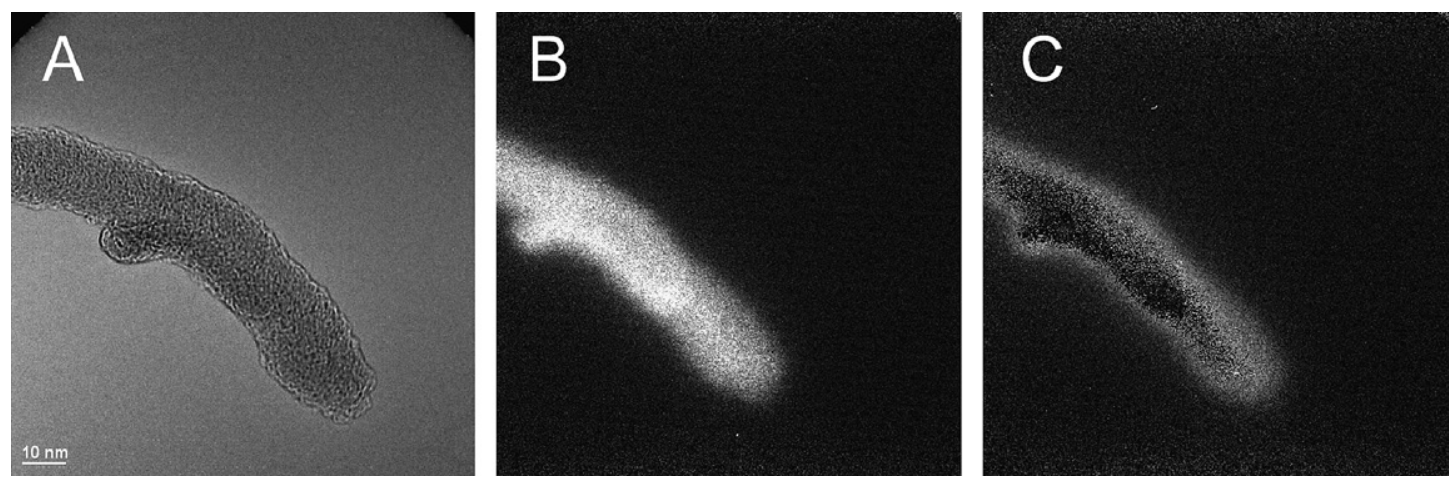

Fig. 4 - Energy filtered TEM micrographs of a NCNT: (A) Zero loss filtered BF TEM micrograph of Co823ACN, (B) carbon K-edge elemental map and (C) nitrogen K-edge elemental map In (B) and (C), light areas represent regions of high concentration. 
A

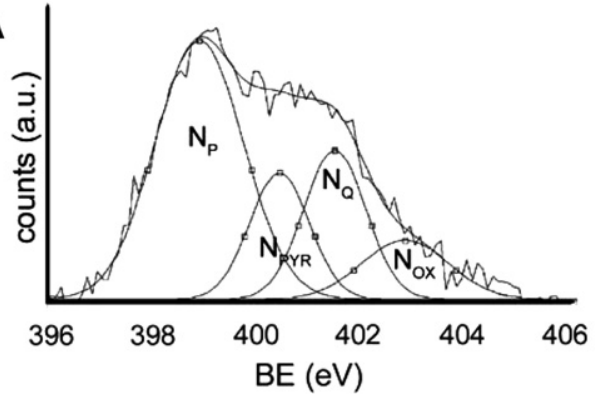

B

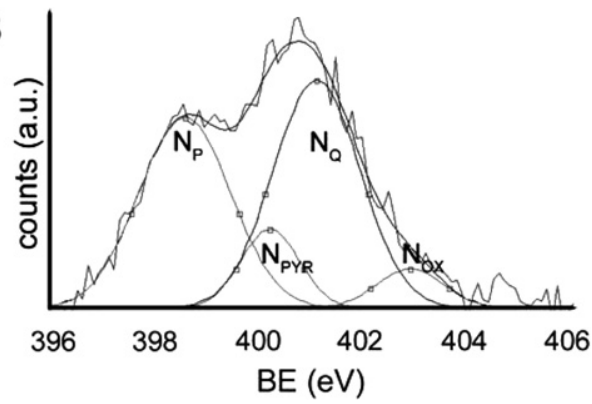

Fig. 5 - XPS N1s spectrum of Co823ACN (A) and Co923ACN (B) with contributions of pyridinic $\mathbf{N}\left(\mathrm{N}_{\mathrm{P}}\right)$, pyrrolic $\mathbf{N}\left(\mathrm{N}_{\mathrm{PYR}}\right)$, quaternary $\mathbf{N}\left(\mathrm{N}_{\mathrm{O}}\right)$ and $\mathbf{N}$-oxides $\left(\mathrm{N}_{\mathrm{OX}}\right)$.

\subsection{Influence of $\mathrm{C} / \mathrm{N}$ source}

From Table 2 it can be seen that NCNT are obtained in good yields (10-25 $\left.\mathrm{g}_{\mathrm{NCNT}} \mathrm{g}_{\mathrm{M}}^{-1}\right)$ when ACN was used as precursor, irrespective of the metal and growth temperature. PYR shows high yields over Fe catalysts $\left(42-48 g_{\text {NCNT }} g_{M}^{-1}\right)$, however only at low temp $(923 \mathrm{~K})$ NCNT were observed. In general with PYR a high amount of amorphous material was observed. The yield of NCNT using DMF was low (2-4 $\left.g_{\text {NCNT }} g_{M}^{-1}\right)$ but the materials were very pure.

The influence of the growth gas (ACN, PYR, DMF) on the morphology of NCNT is most clearly seen over Co catalysts (Fig. 6A-C) but the statements made here also hold for Ni catalysts. From ACN and DMF (Fig. 6A and B) tubes with a diameter of $14-16 \mathrm{~nm}$ were grown. The figure also indicates a lighter centre part of all tubes indicating a hollow interior. In the high resolution TEM (Fig. 7) of a typical NCNT produced from DMF the individual graphene layers with a spacing of $3.4 \AA$, which is typical for graphite like material [44] are clearly detected.

The morphology of the NCNT prepared using the iron catalysts were bamboo like and as such different as compared to the NCNT obtained with the cobalt- and nickel catalysts. This will be discussed in more detail in Section 3.3.

When relating the amount of $\mathrm{N}$ incorporated in the NCNT with the $\mathrm{C} / \mathrm{N}$-source no clear relation can be found. For example over the iron catalysts it seems the amount of nitrogen incorporation increased in the order ACN > PYR while over Co this order is reversed. Please note that this statement is based on taking into account all types of carbon (flagged, respectively, as,+ \pm or as - in Table 2 ).

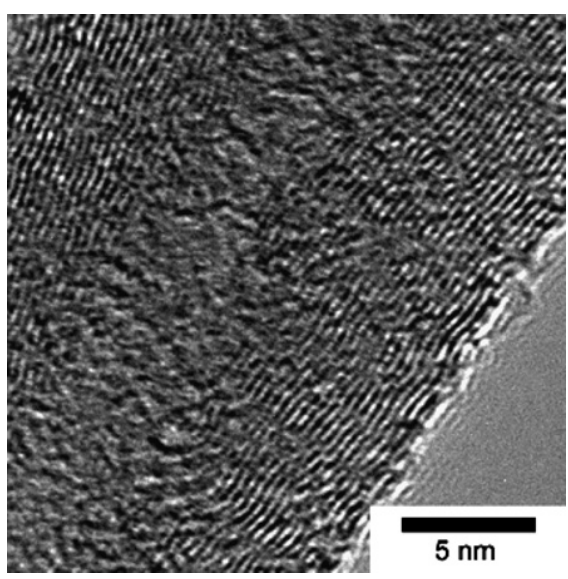

Fig. 7 - High resolution micrograph of NCNT graphene layers from Co923DMF.

\subsection{Influence of growth metal}

From Table 2 it becomes clear that the highest yields of NCNT were obtained with the iron catalyst, between 23 and $42 \mathrm{~g}_{\mathrm{NCNT}} \mathrm{g}_{\mathrm{M}}^{-1}$ using ACN or PYR. It appeared that the order is $\mathrm{Fe}>\mathrm{Co}>\mathrm{Ni}$ when ACN or PYR was used. DMF resulted in a too low amount of NCNT to draw firm conclusions on.

Fig. 8 shows typical transmission electron micrographs of NCNT grown from ACN over Fe, Co or Ni catalysts at $923 \mathrm{~K}$. All NCNT show tube-like material of comparable diameter between 12 and $17 \mathrm{~nm}$. The contrast between the centre and the edge suggests hollow tubes, as discussed above. This was also
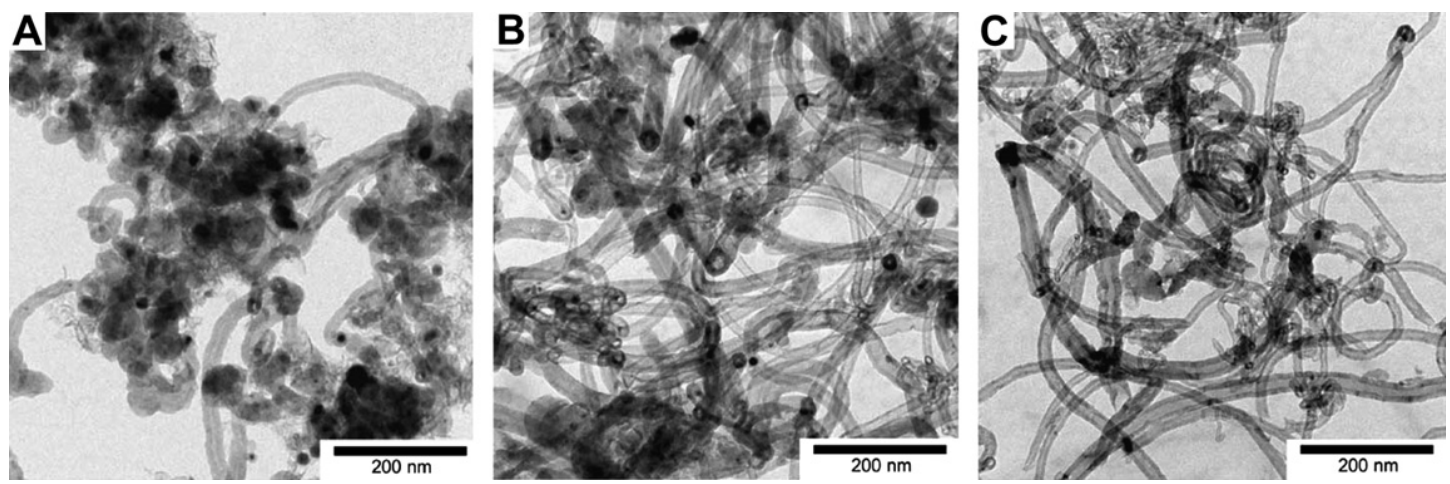

Fig. 6 - TEM micrographs of NCNT grown from Co at $923 \mathrm{~K}$ using PYR (A), DMF (B) and ACN (C). 

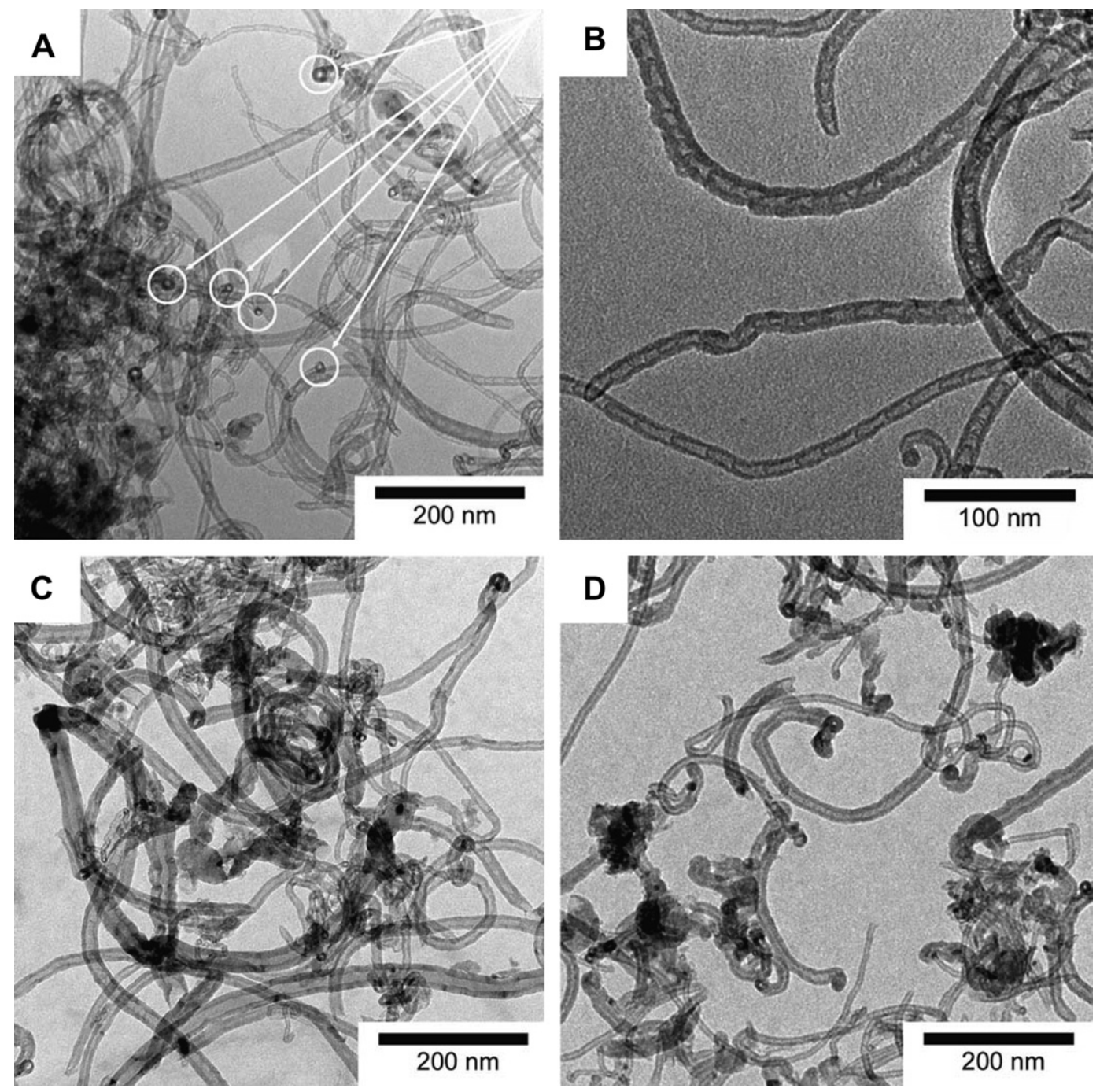

Fig. 8 - TEM micrographs of NCNT obtained from ACN at $923 \mathrm{~K}$ using Fe (A), detail of Fe923ACN showing bamboo morphology (B), Co (C) and Ni (D) as growth catalyst.

supported by on-top views of the NCNT as indicated by circles and arrows. Figs. 8A and B shows NCNT grown from ACN at $923 \mathrm{~K}$ using an Fe catalyst. From Fig. $8 \mathrm{~B}$ it is clear that the tubes grown from iron show compartments, these are the so called bamboo shaped NCNT $[45,46]$. This type of morphology is typically obtained with the Fe catalyst, irrespective of the precursor or the growth temperature and contrasts the morphology of NCNT obtained over Ni and Co (Figs. 8C and D) which comprised parallel tubes. The compartments appear as stacked cups with a wall thickness between 4 and $7 \mathrm{~nm}$. The NCNT grown from ACN over Co and Ni, respectively, consist of multiwalled tubes, with a wall thickness (dark edges) between 5 and $10 \mathrm{~nm}$.

In general, the average diameter of NCNT prepared over the HDP catalysts is fairly constant with an average between 12 and $19 \mathrm{~nm}$ for all C/N sources regardless of the catalyst used (except for CoPYR1023). The diameter distribution of NCNT obtained with Ni is narrower (around 4-28 nm) as compared to the NCNT obtained with Fe or Co (5-62 nm).

In some cases amorphous carbon was observed (purity \pm or - in Table 2). Amorphous carbon can be formed either from gas phase decomposition (pyrolysis) of the precursors or over small metal particles that were too reactive to form a nanostructured carbon $[45,47,48]$ but became encapsulated by (amorphous) coke. To investigate the role of particle size Niand Co catalysts were prepared with large, i.e., less reactive metal particles (see Table 1). From these catalysts NCNT were grown under conditions which resulted with the small particles in amorphous materials (see Fig. 2b) i.e., PYR as precursor and at higher temperatures $(>923 \mathrm{~K})$. Scanning electron micrographs of NCNT grown with the $\mathrm{Co} / \mathrm{SiO}_{2}-\mathrm{WI}$ catalyst are displayed in Fig. 9. As can be seen in this figure, no amorphous carbon had been formed during growth and only NCNT with large diameter were obtained, the average diameter being $80 \mathrm{~nm}$. This also holds for the NCNT prepared over Ni/ $\mathrm{SiO}_{2}-\mathrm{WI}$.

\section{Discussion}

Depending on the reaction conditions either very pure NCNT were prepared or significant amounts of amorphous materi- 

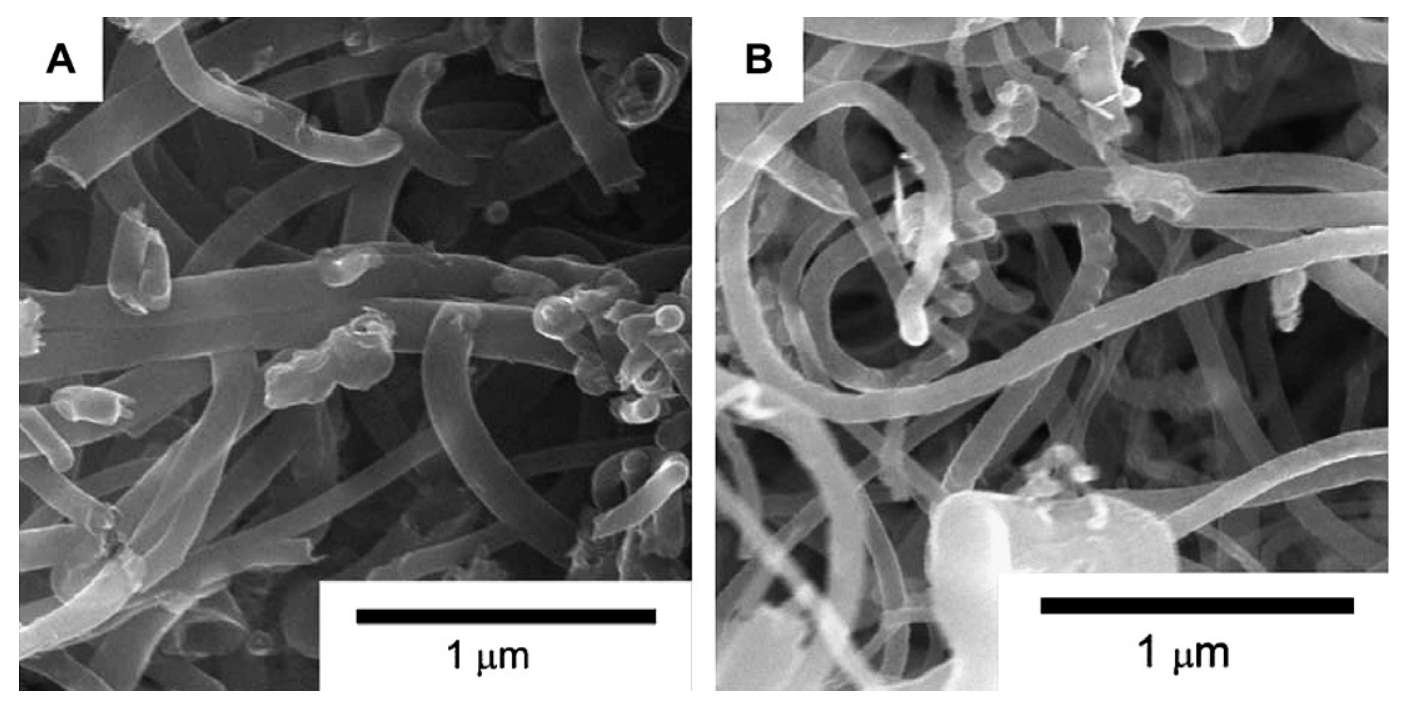

Fig. 9 - SEM images of NCNT obtained from PYR using Co/SIO $-\mathrm{IW}$ at $1023 \mathrm{~K}(\mathrm{~A})$ and $1123 \mathrm{~K}$ (B).

als were obtained (Table 2). In this section we discuss the results concerning NCNT unless stated otherwise. To explain the influence of the different synthesis parameters on NCNT properties we first discuss the stability of metal-carbides and metal nitrides since we propose that these relate to the synthesis of NCNT. Subsequently we discuss the chemical properties of the NCNT, like the amount and type of nitrogen incorporated, followed by a discussion on the physical properties of the NCNT, like morphology and yield.

\subsection{Yield of NCNT}

For the growth of CNT in general three different steps can be envisioned $[4,49]$. First the precursor decomposes on the surface of the growth catalyst resulting in surface carbides and nitrides. In a next step the $\mathrm{C}$ - and $\mathrm{N}$ atoms diffuse through/ over the metal particle followed by nucleation and tube growth.

The stability of the different carbides and nitrides was used as a yardstick for the affinity of the metal for $\mathrm{C}$ and $\mathrm{N}$, respectively. The product yield and composition could be related to the $\Delta G_{\mathrm{f}}^{0}$ of the respective metal-carbides and nitrides. In Fig. 10 the calculated $\Delta G_{\mathrm{f}}^{0}$ values for Fe-, Co- and Ni-carbides and nitrides as function of temperature are displayed. Please note that the $\Delta G_{\mathrm{f}}^{0}$ values were calculated from standard enthalpy and entropy values $[50,51]$ using the relation $\Delta G_{\mathrm{f}}^{0}=\Delta H_{\mathrm{f}}^{0}-T \Delta S_{\mathrm{f}}^{0}$, where the values of $\Delta H_{\mathrm{f}}^{0}$ and $\Delta S_{\mathrm{f}}^{0}$ were treated as temperature independent. According to their phase diagram [52], the crystal structure of the metal particles (Table 1) does not change in the temperature range of NCNT growth, i.e., 823-1123 K, therefore very large changes of the values of $\Delta H_{\mathrm{f}}^{0}$ and $\Delta S_{\mathrm{f}}^{0}$ are not expected and were assumed to be constant. As can be seen from Fig. 10 all $\Delta G_{\mathrm{f}}^{0}$ values are larger than zero, i.e., for $\mathrm{Fe}_{3} \mathrm{C}, \mathrm{Co}_{2} \mathrm{C}$ and $\mathrm{Ni}_{3} \mathrm{C}$, and slowly decreases in the temperature range $800-1200 \mathrm{~K}$. For the formation of (N)CNT a metastable carbide is required which means that the $\Delta G_{\mathrm{f}}^{0}$ is around zero. If $\Delta G_{\mathrm{f}}^{0}$ is very negative the metal-carbide is too stable thereby preventing the nucleation of the (N)CNT. If $\Delta G_{\mathrm{f}}^{0}$ is too positive the interaction between carbon

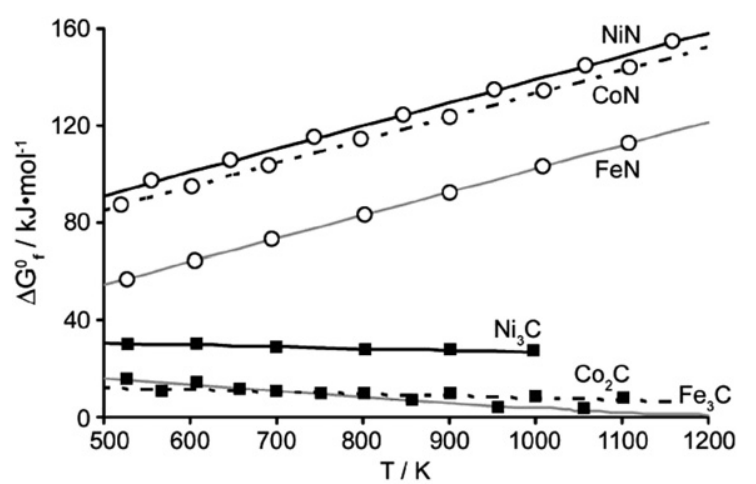

Fig. $10-\Delta G_{f}^{0}$ values per mol C for $\mathrm{Fe}_{3} \mathrm{C}, \mathrm{Co}_{2} \mathrm{C}$ and $\mathrm{Ni}_{3} \mathrm{C}(\square)$ and per mol N for FeN, CoN and NiN (o): Fe (grey line), Co (dashed line), Ni (solid line).

and the metal is too weak and hydrocarbon decomposition does not take place. With increasing temperature $\Delta G_{\mathrm{f}}^{0}$ approaches zero and the formation of $(\mathrm{N}) \mathrm{CNT}$ becomes more favourable. Furthermore, with increasing temperature the reaction rate also increases and therefore higher yields are expected. This is indeed the case (Table 2, yield).

The influence of the thermodynamic stability of the metalnitrides seems to be of minor importance as (N)CNT can still be formed at high temperature $(>1023 \mathrm{~K})$ where the metal-nitrides are unstable (Fig. 10). The reason for this might be found in the fact that nitrogen is only a minority fraction in the NCNT therefore we speculate that the stability of the carbides is decisive. However, when the thermodynamic stability of the metal-carbide alone would be decisive for the yield no differences should be expected for the different $\mathrm{C} / \mathrm{N}$ sources. However, the product yield from ACN is relatively high, between 10 and $25 g_{\text {NCNT }} g_{M}^{-1}$ increasing with increasing temperature. When PYR is used, only high yields are obtained with iron, between 42 and $48 g_{\mathrm{NCNT}} \mathrm{g}_{\mathrm{M}}^{-1}$, whereas with both cobalt and nickel, low yields between 4 and $8 g_{N C N T} g_{M}^{-1}$ are obtained. These results indicate that also other factors, either kinetic 
(such as decomposition rate of the precursor) or thermodynamic (stability of the precursor) influence the NCNT formation process and thus the yield.

For example, it can be speculated that deactivation of the cobalt and nickel catalysts, due to a fast decomposition rate of PYR, is the reason for the observed low yield, which can be explained in terms of the activity of metal particles $[47,48]$. Small metal particles are considered to be more active for the decomposition of the $\mathrm{C} / \mathrm{N}$ precursor than large particles, may contribute to the fast decomposition of PYR leading to encapsulation by carbonaceous material and subsequent deactivation. The less active large particles provide the suitable decomposition rate of PYR which may explain the increase in diameter of the NCNT at $1023 \mathrm{~K}$, i.e., only metal particles of a minimum size sustain NCNT growth while smaller particles are covered with carbon to such an extent that deactivation follows. Experiments of NCNT growth from PYR using $\mathrm{Co}$ and Ni catalysts which were prepared using the wet impregnation method (Fig. 9) pointed out that indeed NCNT can be formed at higher temperatures (1023 and $1123 \mathrm{~K}$ ) when the metal particles are sufficiently large. This indicates that less reactive metal particles, i.e., particles that are sufficiently large and therefore expose to a larger extent the low index planes, are necessary for a controlled decomposition of a reactive $\mathrm{C} / \mathrm{N}$ source as PYR in order to avoid deactivation of the catalyst by a too fast deposition of carbon on the metal surface. The distribution of diameters reflects the appropriate metal particle sizes to sustain NCNT growth. It appears that a size in the range of $5-30 \mathrm{~nm}$ is sufficient to initiate and maintain the growth of NCNT at temperatures between 823 and $1023 \mathrm{~K}$ when $\mathrm{ACN}$ is used as the $\mathrm{C} / \mathrm{N}$ source. However, only at a low growth temperature between 823 and $923 \mathrm{~K}$ NCNT were obtained when PYR or DMF was used. At higher temperatures, i.e., $1023 \mathrm{~K}$ and $1123 \mathrm{~K}$, only amorphous carbon was obtained with the Fe and Ni catalyst when PYR was used as $\mathrm{C} / \mathrm{N}$ source. Please note that the amorphous carbon does not lead to an immediate catalyst deactivation since large amounts of amorphous carbon are formed. This indicates either that the metal particles remain accessible for the reactant or that the carbon itself becomes a centre of decomposition [53].

No significant differences between iron, cobalt and nickel were found with DMF as the $\mathrm{C} / \mathrm{N}$ source. In this case the low yields with a maximum of $4 \mathrm{~g}_{\mathrm{NCNT}} \mathrm{g}_{\mathrm{M}}^{-1}$ might be caused by the thermodynamic stability of the compound towards decomposition, i.e., $\quad \Delta H_{\mathrm{f} D \mathrm{DMF}}^{0}\left(-192 \mathrm{~kJ} \mathrm{~mol}^{-1}\right)<\Delta H_{\mathrm{f} \mathrm{ACN}}^{0}(74$ $\left.\mathrm{kJ} \mathrm{mol}^{-1}\right)<\Delta H_{\mathrm{fPYR}}^{0}\left(140 \mathrm{~kJ} \mathrm{~mol}^{-1}\right)$ [54] which means that DMF is thermodynamically more stable towards decomposition than PYR or ACN.

\subsection{Amount of nitrogen in NCNT}

Elemental mapping of one of the NCNT samples (Co823ACN) indicated that nitrogen was located within the outer few graphene sheets of the NCNT (Fig. 4). The amount of nitrogen incorporated in the NCNT, as well as the amount of nitrogen found in amorphous carbon decreased with increasing growth temperature (Fig. 3). Either the formation of metal-nitrides is more favourable at low growth temperatures or, alternatively, the formation of metal-carbides is more favourable

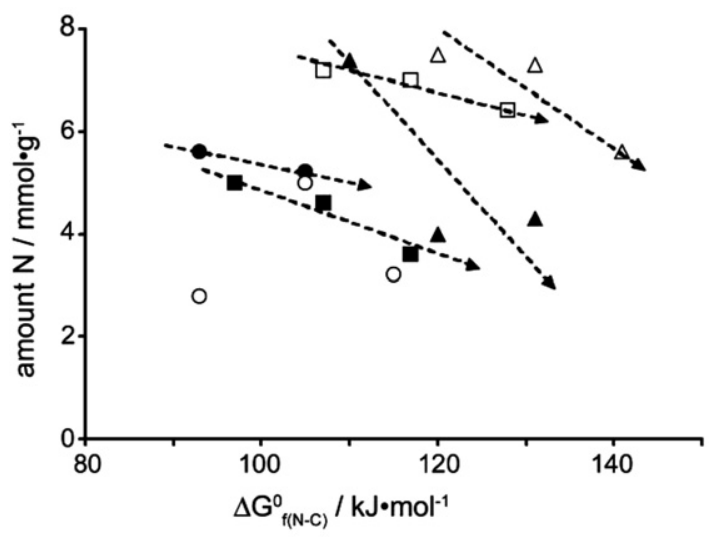

Fig. 11 - Amount of nitrogen in NCNT as function of $\Delta \mathbf{G}_{\mathrm{f}}^{0}(\mathbf{N}-\mathbf{C})=\Delta \mathbf{G}_{\mathrm{f}(\mathbf{N})}^{0}-\Delta \mathbf{G}_{\mathrm{f}(\mathbf{C})}^{0}$ for Fe-ACN $(\bullet)$, Fe-PYR $(\bigcirc)$,

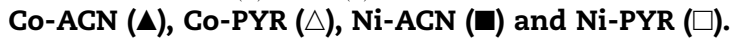

at high growth temperatures. As can be seen in Fig. 10 the $\Delta G_{\mathrm{f}}^{0}$ values for metal nitrides increase within the temperature range $500-1200 \mathrm{~K}$ while the $\Delta G_{\mathrm{f}}^{0}$ for carbides decrease. This means that indeed the formation of carbides is more favoured over the formation of nitrides at more elevated temperatures which might explain the low amount of nitrogen incorporated at higher growth temperatures. In Fig. 11 the amount of nitrogen incorporated in the NCNT is displayed as function of the $\Delta G_{\mathrm{f}}^{0}(\mathrm{~N}-\mathrm{C})=\Delta G_{\mathrm{f}(\mathrm{N})}^{0}-\Delta G_{\mathrm{f}(\mathrm{C})}^{0}$, i.e., the difference between the stability of the metal nitride minus the stability of the metal-carbide. With the exception of the NCNT grown from PYR over Fe, all NCNT show a decrease in nitrogen content with the increase of the $\Delta G_{f}^{0}(N-C)$ value. Clearly, enhanced stability of the metal nitride relative to the metal-carbide assists in the incorporation of nitrogen. Although the amount of nitrogen incorporated in the NCNT grown from PYR is in most cases higher than those grown from ACN, the trend is generally the same. This suggests that beside the energy differences between metal-carbide and nitride formation also other factors are important, for example the thermodynamic stability of the $\mathrm{C} / \mathrm{N}$ precursor and (surface) concentration of carbides and nitrides.

\subsection{Type of nitrogen in NCNT}

The type of nitrogen found in the NCNT changes with the increase of the growth temperature. Pyridinic $\mathrm{N}$ is predominantly present when NCNT are grown at a low temperature of $823 \mathrm{~K}$ while more quaternary $\mathrm{N}$ is found at high temperatures between 1023 and $1123 \mathrm{~K}\left(\mathrm{~N}_{\mathrm{P}} / \mathrm{N}_{\mathrm{Q}}\right.$ ratio in Table 2). This trend is observed for the NCNT grown from ACN and PYR and is in line with other observations reported in literature for nitrogen-containing chars $[34,55,56]$. Since in the latter studies $\mathrm{N}$-containing chars were heated it was concluded that in the temperature range between 873 and $1073 \mathrm{~K}$ pyridinic $\mathrm{N}$ was converted to the more thermally stable quaternary $\mathrm{N}$. However, it can be disputed whether the increase of quaternary $\mathrm{N}$ between 1023 and $1123 \mathrm{~K}$ in this research is also the result of transformation of pyridinic $\mathrm{N}$ into quaternary $\mathrm{N}$. Because in our study quaternary $\mathrm{N}$ was found at high $(1123 \mathrm{~K})$ and low $(823 \mathrm{~K})$ growth temperatures it is possible 
that at least part of the quaternary $\mathrm{N}$ is formed at these directly.

\subsection{Morphology of NCNT}

Different structures of carbon nanomaterials have been reported in literature like fishbone, tubes and bamboo structures $[36,44]$. The reason for these differences should be found in details of the mechanism of CNT/NCNT growth and thus be related to metal particle shape, carbon diffusion or growth direction, i.e., from the tip of a metal particle separated from its support or from the base of a metal particle still on its support. Possibly there are several factors contributing to the occurrence of different structures. In this paragraph the difference in NCNT morphology obtained from $\mathrm{Fe} / \mathrm{Al}_{2} \mathrm{O}_{3}$, $\mathrm{Co} / \mathrm{SiO}_{2}$ and $\mathrm{Ni} / \mathrm{SiO}_{2}$ will be discussed. The Fe catalyst was supported by alumina and not by silica to prevent the formation of iron silicates during reduction [57-59]. Despite the fact that iron is deposited on a different support than cobalt or nickel we believe that the iron particle is the determining factor for the formation of NCNT with bamboo morphology since this structure was obtained by various supported and unsupported Fe catalysts $[17,18,20,25,31,46]$. The formation mechanism of the bamboo structure is heavily debated. Both the base growth mechanism $[22,46]$ and the tip growth mechanism $[23,60]$ were used to explain this morphology. Which one occurs is believed to be determined by the strength of the metal-support bond [61,62]. It has been suggested that nitrogen may enhance bamboo structures to be formed [63-65]. However, since straight tubes were formed when $\mathrm{Co}$ or Ni was used as growth catalyst it seems unlikely that there is an effect of nitrogen always causing bamboo structures.

A possible explanation for the structural difference in NCNT obtained with $\mathrm{Fe}$ and $\mathrm{Co} / \mathrm{Ni}$, i.e., respectively, bamboo and straight tubes, may be caused by the thermodynamic stabilities of the metal-carbides (Fig. 10). From literature it is known that especially with iron stable carbides can be formed, e.g., $\mathrm{Fe}_{3} \mathrm{C}$ (cementite) $[66,67]$. When relative stable iron carbide can be formed it is likely that a high carbon concentration exists at the metal surface as well as in the bulk. This means that the chance of forming a graphitic envelope around Fe is higher than for the thermodynamically less stable Co- or Ni carbides. As was suggested by Hoogenraad et al. [68] this will cause the growth of (N)CNT on an Fe surface to be more pulsating opposed to a more continuous growth in the case of Co or Ni (Fig. 12).

The $\mathrm{C} / \mathrm{N}$ source is decomposed at the metal surface into metal-carbides and -nitrides. Because of the high carbon coverage of the iron surface $[59,67]$ and the stability of the bulk carbide, migration of carbon over the surface is probably a more dominant process than diffusion through the metal particle and as a result a carbon layer is formed on the iron surface. At certain carbide concentration the Fe particle pushes itself out of the carbon envelope which results in a 'clean' Fe surface and the whole process can repeat itself [68]. This causes a pulsated growth of bamboo shaped NCNT. In the case of $\mathrm{Co}$ and $\mathrm{Ni}$, represented by Fig. 12B, metal-carbides and nitrides are formed in the same manner as with Fe. However, forming thermodynamically less stable carbides than

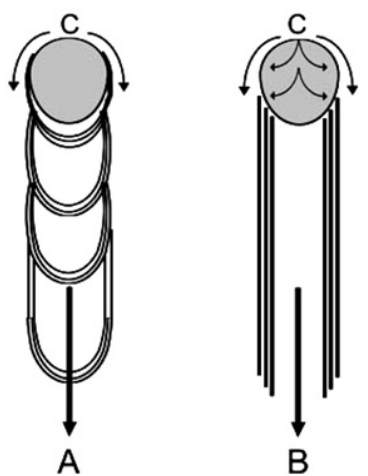

Fig. 12 - schematic representation of the NCNT growth process from Fe (A) and Ni or Co (B).

iron, NCNT are formed in a more continuous manner on cobalt- and nickel particles as carbon diffuses/migrates through/over the metal and is segregated more readily.

\section{Conclusions}

Nitrogen-containing carbon nanotubes have been prepared by catalytic vapour deposition of acetonitrile, pyridine and $\mathrm{N}, \mathrm{N}$ dimethylformamide over supported iron-, cobalt- and nickel catalysts. The influence of the synthesis parameters, i.e., temperature, C/N source and catalyst, on the yield, morphology and $\mathrm{C} / \mathrm{N}$ composition of the NCNT was studied. Acetonitrile appeared to be most versatile for NCNT synthesis over a broad temperature range (823-1023 K), regardless of the catalyst used. The steady formation of NCNT can only be achieved when the decomposition rate of the $\mathrm{C} / \mathrm{N}$ precursor, the diffusion rate of the carbon and nitrogen atoms over/through the metal particle and the formation of the tube are in balance. This is interplay between stability of the reactant, metal particle size and metal structure.

The N/C ratio of the NCNT decreased with increasing temperature for all $\mathrm{C} / \mathrm{N}$ sources and growth catalysts used. This could be related to the difference between $\Delta G_{f}$ of the respective metal-carbides and nitrides; with increasing temperature the formation of metal-carbides becomes more favorable than the formation of metal nitrides. Moreover, the $\mathrm{N}_{\mathrm{P}} / \mathrm{N}_{\mathrm{Q}}$ ratio also decreased with increasing temperature.

With the cobalt- and nickel catalysts multiwalled nanotubes were formed while bamboo type tubes were formed over iron. This difference in morphology of the NCNT obtained from the was explained by the difference in thermodynamic stability of the metal-carbides. Fe-carbides are more stable compared to the Ni- and Co-carbides which might result in a pulsating growth over Fe while $\mathrm{Ni}$ and Co grow in a smooth manner.

\section{Acknowledgements}

C. van der Spek for TEM analysis and M. Versluijs-Helder for SEM analysis. This investigation is supported by The Netherlands Organization for Scientific Research Project 700.50.520. 


\section{R E F E R E N C E S}

[1] Baughman RH, Zakhidov AA, de Heer WA. Science 2002;297:787-92.

[2] Avouris P. Chem Phys 2002;281:429-45.

[3] Kreupl F, Graham AP, Duesberg GS, SteinHögl W, Liebau M, Unger E, et al. Microelectron Eng 2002;64:399-408.

[4] de Jong KP, Geus JW. Catal Rev Sci Eng 2000;42(4):481-510.

[5] Serp P, Corrias M, Kalck P. Appl Catal A: Gen 2003;253:337-58.

[6] Bitter JH, van der Lee MK, Slotboom AGT, van Dillen AJ, de Jong KP. Catal Lett 2003;89(1-2):139-42.

[7] Keller N, Maksimova NI, Roddatis VV, Schur M, Mestl G, Butenko YV, et al. Angew Chem Int Ed 2002;41(11):1885-8.

[8] van Dommele S, de Jong KP, Bitter JH. Chem Commun 2006:4859-61.

[9] Ewels CP, Glerup M. J Nanosci Nanotechnol 2005;5:1345-63.

[10] Terrones M, Grobert N, Terrones H. Carbon 2002;40:1665-84.

[11] Suenaga K, Johansson MP, Hellgren N, Broitman E, Wallenberg LR, Colliex C, et al. Chem Phys Lett 1999;300:695-700.

[12] Belz T, Bauer A, Find J, Günter M, Herein D, Möckel H, et al. Carbon 1998;236(5-6):731-41.

[13] Hellgren N, Johansson MP, Broitman E, Hultman L, Sundgren JE. Phys Rev B 1999;59(7):5162-9.

[14] Le Normand F, Hommet J, Szörényi T, Fuchs C, Fogarassy E. Phys Rev B 2001;64:2354161-15.

[15] Hu J, Yang P, Lieber CM. Phys Rev B 1998;57(6):R3185-8.

[16] Kudashov AG, Okotrub AV, Bulusheva LG, Asanov IP, Shubin YV, Yudanov NF, et al. J Phys Chem B 2004;108:9048-53.

[17] Choi HC, Park J, Kim B. J Phys Chem B 2005;109:4333-40.

[18] Lee YT, Kim NS, Park J, Han JB, Choi YS, Ryu H, et al. Chem Phys Lett 2003;372:853-9.

[19] Terrones M, Benito AM, Manteca-Diego C, Hsu WK, Osman OI, Hare JP, et al. Chem Phys Lett 1996;257:576-82.

[20] Glerup M, Castignolles M, Holzinger M, Hug G, Loiseau A, Bernier P. Chem Commun 2003:2542-3.

[21] Kim SY, Lee J, Na CW, Park J, Seo K, Kim B. Chem Phys Lett 2005;413:300-5.

[22] Jiang J, Feng T, Cheng X, Dai L, Cao G, Jiang B, et al. Nucl Instrum Meth B 2006;244:327-32.

[23] Trasobares S, Stéphan O, Colliex C, Hsu WK, Kroto HW, Walton DRM. J Chem Phys 2002;116(20):8966-72.

[24] Terrones M, Redlich P, Grobert N, Trasobares S, Hsu WK, Terrones H, et al. Adv Mater 1999;11(8):655-8.

[25] Tang C, Bando Y, Goldberg D, Xu F. Carbon 2004;42:2625-33.

[26] Matsui T, Yudasaka M, Kikuchi R, Ohki Y, Yoshimura S. Mater Sci Eng B 1995;29:220-2.

[27] Qiu Y, Gao L. Chem Commun 2003:2378-9.

[28] Miyamoto Y, Cohen ML, Louie SG. Solid State Commun 1997;102(8):605-8.

[29] dos Santos MC, Alvarez F. Phys Rev B 1998;58(20):13918-24.

[30] Snis A, Matar SF. Phys Rev B 1999;60:10855-63.

[31] Louis B, Gulino G, Vieira R, Amadou J, Dintzer T, Galvagno S, et al. Catal Today 2005;102-103:23-8.

[32] Fan YY, Cheng HM, Wei YL, Su G, Shen ZH. Carbon 2000;38:789-95.

[33] Raymundo-Piñero E, Cazorla-Amorós D, Linares-Solano A, Find J, Wild U, Schlögl R. Carbon 2002;40:597-608.

[34] Pels JR, Kapteijn F, Moulijn JA, Zhu Q, Thomas KM. Carbon 1995;33(11):1641-53.
[35] Czerw R, Terrones M, Charlier JC, Blasé X, Foley B, Kamalakaran R, et al. Nano Lett 2001;1(9):457-60.

[36] Deck CP, Vecchio K. Carbon 2006;44:267-75.

[37] Schaper AK, Hou H, Greiner A, Phillipp F. J Catal 2004;222:250-4.

[38] Sun XC, Reyes-Gasga J, Dong XL. Mol Phys 2002;100(19):3147-50.

[39] Nishitani SR, Ishihara KN, Suzuki RO, Shingu PH. J Mater Sci Lett 1985;4:872-5.

[40] van der Lee MK, van Dillen AJ, Bitter JH, de Jong KP. J Am Chem Soc 2005;127:13573-82.

[41] Bezemer GL, Radstake PB, Falke U, Oosterbeek H, van Dillen AJ, de Jong KP. J Catal 2006;237:152-61.

[42] Gammon WJ, Kraft O, Reilly AC, Holloway BC. Carbon 2003;41:1917-23.

[43] Kelemen SR, Gorbaty ML, Kwiatek PJ. Energeia 1995;6(5):1-4.

[44] Teo KBK, Singh C, Chhowalla M, Milne WI. Encyclopedia Nanosci Nanotechnol 2004;1:665-86.

[45] Otsuka K, Ogihara H, Takenaka S. Carbon 2003;41:223-33.

[46] Lee CJ, Park J. Appl Phys Lett 2000;77(21):3397-9.

[47] Toebes ML, Bitter JH, van Dillen AJ, de Jong KP. Catal Today 2002;76:33-42.

[48] Park C, Keane MA. Langmuir 2001;17:8386-96.

[49] Pérez-Cabero M, Romeo E, Royo C, Monzón A, Guerrero-Rúz A, Rodríguez-Ramos I. J Catal 2004;224:197-205.

[50] Shatynski SR. Oxid Metal 1979;13(2):105-18.

[51] Guillermet AF, Frisk K. J Alloy Comp 1994;203:77-89.

[52] de Boer FR, Boom R, Mattens WCM, Miedema AR, Niessen AK. Cohesion in metals, transition metal alloys. In: de Boer FR, Pettifor DG, editors. Amsterdam: Elsevier Science Publishers B.V; 1989. p. 219-315.

[53] Kovalevski VV, Safronov AN. Carbon 1998;36(7):963-8.

[54] Lide DR. Handbook of chemistry and physics. 85th ed. Boca Raton (Florida, USA): CRC press; 2004

[55] Stanczyk K, Dziembaj R, Piwowarska Z, Witkowski S. Carbon 1995;33(10):1383-92.

[56] Choi HC, Bae SY, Jang WS, Park J, Song HJ, Shin HJ, et al. J Phys Chem B 2005;109:1683-8.

[57] Zhang CH, Wan HJ, Yang Y, Xiang HW, Li YW. Catal Commun 2006;7:733-8.

[58] Wielers AFH, Kock AJHM, Hop CECA, Geus JW, van der Kraan AM. J Catal 1989;117:1-18.

[59] Hayakawa H, Tanaka H, Fujimoto K. Appl Catal A 2006;310:24-30.

[60] Sinnot SB, Andrews R, Qian D, Rao AM, Mao Z, Dickey EC, et al. Chem Phys Lett 1999;315:25-30.

[61] Cassell AM, Raymakers JA, Kong J, Dai H. J Phys Chem B 1999;103:6484-92.

[62] Baker RTK. Carbon 1989;27(3):315-23.

[63] Lin CH, Chang HL, Hsu CM, Lo AY, Kuo CT. Diam Relat Mater 2003;12:1851-7.

[64] Chang HL, Lin CH, Kuo CT. Diam Relat Mater 2002;11(36):793-8.

[65] Ma X, Wang E, Jefferson DA, Chen J, Deng S, Xu N, et al. Appl Phys Lett 1999;75:3105-7.

[66] Avdeeva LB, Reshetenko TV, Ismagilov ZR, Likholobov VA. Appl Catal A: Gen 2002;228:53-63.

[67] Chiou Jr WC, Carter EA. Surf Sci 2003;530:87-100.

[68] Hoogenraad MS. Growth and utilization of carbon fibrils. Utrecht, The Netherlands, Utrecht University, PhD thesis, 1995. 